\title{
ABSOLUTE SUMMABILITY OF A SERIES ASSOCIATED WITH A FOURIER SERIES
}

\section{H. P. DIKSHIT}

1. Let $f(t)$ be a periodic function with period $2 \pi$, integrable $(L)$ over $(-\pi, \pi)$ and

$$
f(t) \sim \frac{1}{2} a_{0}+\sum_{n=1}^{\infty}\left(a_{n} \cos n t+b_{n} \sin n t\right)=\sum_{n=0}^{\infty} A_{n}(t) .
$$

We write

$$
\begin{aligned}
\phi(t) & =\{f(\chi+t)+f(\chi-t)\} / 2 ; \quad \phi^{*}(t)=\phi(t)-s ; \\
A_{n}^{*}(t) & =\left(s_{n}-s\right) / n, \quad n=1,2, \cdots,
\end{aligned}
$$

where $s_{n}=\sum_{k=0}^{n} A_{k}(t)$ and $s$ is an appropriate number independent of $n . K$, denotes a positive constant, not necessarily the same at each occurrence.

If $\left\{p_{n}\right\}$ is a given sequence of constants, real or complex, such that $P_{n}=p_{0}+p_{1}+\cdots+p_{n} \neq 0, P_{-1}=0$, then

$$
t_{n}=\sum_{k=0}^{n} P_{k} a_{n-k} / P_{n}
$$

defines the sequence $\left\{t_{n}\right\}$ of $\left(N, p_{n}\right)$ means of $\sum_{n} a_{n}$. The series $\sum_{n} a_{n}$ is said to be summable $\mid N$, $p_{n} \mid$, if $\left\{t_{n}\right\} \in B V$, i.e., $\sum_{n}\left|t_{n}-t_{n-1}\right| \leqq K$.

The $(C)$-summability of the series $\sum_{n=1}^{\infty} A_{n}^{*}(t)$ has been discussed in detail by Hardy and Littlewood [3], while a necessary and sufficient condition for its convergence is given by Zygmund [7, p. 61]. Concerning the $|C|$-summability of the series $\sum_{n=1}^{\infty} A_{n}^{*}(t)$, Mohanty and Mohapatra [4, Theorem 3] have proved the following.

Theorem A. If $\left|\phi^{*}(t)\right| / t$ is integrable in $(0, \pi)$, then $\sum_{n=1}^{\infty} A_{n}^{*}(x)$ is summable $|C, \delta|, \delta>0$.

In the present paper we study the $\left|N, p_{n}\right|$ summability of the series $\sum_{n=1}^{\infty} A_{n}^{*}(x)$. We prove

THEOREM. If $\left|\phi^{*}(t)\right| / t$ is integrable in $(0, \pi)$ and $\left\{p_{n}\right\}$ is a positive sequence such that $\left\{(n+1) p_{n} / P_{n}\right\} \in B V, \quad\left\{P_{n}^{-1} \sum_{k=0}^{n} P_{k} /(k+1)\right\}$ $\in B V$, then $\sum_{n=1}^{\infty} A_{n}^{*}(x)$ is summable $\left|N, p_{n}\right|$.

It may be observed that Theorem A follows as a special case of our

Received by the editors October $8,1968$. 
theorem since $\left|N, p_{n}\right|$ summability, when

$$
p_{n}=\left(\begin{array}{c}
n+\delta-1 \\
\delta-1
\end{array}\right)=\Gamma(n+\delta) /\{\Gamma(n+1) \Gamma(\delta)\} ; \delta>0,
$$

is the same as $|C, \delta|$ summability.

2. We need the following lemma.

Lemma. If $\left\{p_{n}\right\}$ satisfies the hypotheses of the Theorem, then uniformly in $0<t \leqq \pi$

$$
\sum_{n=1}^{\infty}|g(n, t)|=\sum_{n=1}^{\infty}\left|\frac{1}{P_{n} P_{n-1}} \sum_{k=0}^{n-1}\left(P_{n} p_{k}-p_{n} P_{k}\right) \frac{\sin \left(n-k+\frac{1}{2}\right) t}{n-k}\right| \leqq K .
$$

Proof. The Lemma follows from the proof of $\Sigma \leqq K$ in [1, p. 168], when we observe that its proof remains valid even if we replace $\sin (n-k) t$ in the expression for $\Sigma$, by $\sin \left(n-k+\frac{1}{2}\right) t$.

3. Proof of the Theorem. For $\sum_{n} A^{*}(x)$ we have

$$
\begin{aligned}
t_{n}-t_{n-1} & =\sum_{k=0}^{n}\left(\frac{P_{k}}{P_{n}}-\frac{P_{k-1}}{P_{n-1}}\right) A_{n-k}^{*}(\chi) \\
& =\frac{1}{P_{n} P_{n-1}} \sum_{k=0}^{n-1}\left(P_{n} p_{k}-p_{n} P_{k}\right) A_{n-k}^{*}(\chi),
\end{aligned}
$$

and $[6, \$ 13.2]$,

$$
A_{n}^{*}(x)=\frac{1}{n \pi} \int_{0}^{\pi} \phi^{*}(t)\left\{\sin \left(n+\frac{1}{2}\right) t / \sin (t / 2)\right\} d t .
$$

Thus, using the notation introduced in the Lemma, we have

$$
\sum_{n}\left|t_{n}-t_{n-1}\right| \leqq \int_{0}^{\pi}\left\{\sum_{n}|g(n, t)|\right\} \frac{\left|\phi^{*}(t)\right|}{t} \frac{t}{\sin (t / 2)} d t \leqq K,
$$

by virtue of the Lemma and the hypothesis that $\left|\phi^{*}(t)\right| / t$ is integrable in $(0, \pi)$. This proves the Theorem.

REMARKs. The fact that it is possible to replace the hypothesis: " $\left\{p_{n}\right\}$ is a positive sequence" in the Lemma by the lighter hypothesis: " $\left\{p_{n}\right\}$ is any sequence and $P_{n}^{*}=\sum_{k=1}^{n}\left|p_{k}\right|=O\left(\left|P_{n}\right|\right)$," leading to a more general version of our Theorem, follows from a very recent result of the present author [2], which shows that the hypothesis: $\sum_{k=1}^{n} k\left|p_{k}-p_{k-1}\right|=O\left(\left|P_{n}\right|\right)$, used by Si-Lei in [5] follows from the other hypotheses of his result [5, Theorem 1]. 


\section{REFERENCES}

1. H. P. Dikshit, Absolute summability of a Fourier series by Nörlund means, Math. Z. 102 (1967), 166-170.

2. - On the absolute Nörlund summability of a Fourier series and its conjugate series, Ködai Math. Som. Rep. 20 (1968), 448-453.

3. G. H. Hardy and J. E. Littlewood, The allied series of a Fourier series, Proc. London Math. Soc. 24 (1926), 211-246.

4. R. Mohanty and S. Mohapatra, On the absolute convergence of a series associated with a Fourier series, Proc. Amer. Math. Soc. 7 (1956), 1049-1053.

5. W. Si-Lei (Szu-Lei), On the absolute Nörlund summability of a Fourier series and its conjugate series, Acta Math. Sinica 15 (1965), 281-295.

6. E. C. Titchmarsh, The theory of functions, Oxford University Press, New York, 1957.

7. A. Zygmund, Trigonometric series, Monogr. Mat., Bd. 5, Warsaw, 1935.

University of Allahabad, Allahabad, India 